BULLETIN Bulletin hispanique

HISPANIQUE Université Michel de Montaigne Bordeaux

118-1 | 2016

La Guerre Civile espagnole aujourd'hui (1936-2016)

\title{
Sobre mitos y falacias de la Guerra Civil que aún persisten
}

Ángel Viñas

\section{(2) OpenEdition}

Journals

\section{Edición electrónica}

URL: http://journals.openedition.org/bulletinhispanique/4207

DOI: 10.4000/bulletinhispanique.4207

ISSN: 1775-3821

\section{Editor}

Presses universitaires de Bordeaux

\section{Edición impresa}

Fecha de publicación: 15 julio 2016

Paginación: 49-64

ISBN: 979-10-300-0058-0

ISSN: 0007-4640

\section{Referencia electrónica}

Ángel Viñas, «Sobre mitos y falacias de la Guerra Civil que aún persisten », Bulletin hispanique [En línea], 118-1 | 2016, Publicado el 15 julio 2019, consultado el 07 septiembre 2019. URL : http:// journals.openedition.org/bulletinhispanique/4207 ; DOI : 10.4000/bulletinhispanique.4207 


\title{
Sobre mitos y falacias de la Guerra Civil que aún persisten
}

\author{
ÁNGEL VIÑ̃As \\ Universidad Complutense de Madrid
}

Cet article passe en revue les thèmes les plus importants propagés par des auteurs que l'on peut qualifier de néo-franquistes. Il examine les circonstances qui ont favorisé la résurgence, dans l'Espagne actuelle, de mythes forgés par la dictature franquiste. L'article met aussi en relief l'intérêt du concept de "projection " pour expliquer ce phénomène.

Mots clés: Guerre Civile espagnole, méthodologie, franquisme, historiographie.

Este artículo pasa revista a los ejemplos más importantes que propagan autores genéricamente caracterizados de «neo-franquistas». Se examinan las circunstancias que han facilitado un revival en la España actual de los mitos acuñados por la dictadura franquista. Se subraya el interés del concepto de «proyección» para explicar tal fenómeno.

Palabras claves: Guerra Civil española, metodología, franquismo, historiografía.

This article lists the most important themes propagated by authors we can call neopro Franco. It examines the circumstances that favoured the resurgence, in present Spain, of myths wrought by Franco's dictatorship. It also puts into light the interest of the concept of «projection» to explain this phenomenon.

Keywords: Spanish Civil War, methodology, Francoism, historiography.

E diccionario de la Real Academia Española define el término mito con cuatro acepciones. Aquí solo la cuarta es pertinente: «Persona o cosa a las que se atribuyen cualidades o excelencias que no tienen, o bien una realidad de la que carecen». El aspecto clave se reproduce en itálicas. También define falacia con dos acepciones. La primera equivale a «engaño, fraude o mentira». La segunda al «hábito de emplear falsedades». La Academia añade una 
cualificación: el intento de dañar a alguien. En cuanto a la guerra civil se trata, pues, de asertos que no corresponden a la realidad de los "hechos» con el fin de influir, con ánimo de dolo, en el lector no especialista. Sustituyen el resultado de la labor histórica por afirmaciones que lo ignoran, tergiversan o subvierten.

Lo que hoy se conoce sobre la guerra civil tiene poco que ver con los planteamientos que, tanto en España como en el extranjero, dominaron a lo largo de la dictadura franquista. En España este cambio ha sido función de la desaparición de la censura y de la restauración de la libertad de expresión, de la creciente apertura de archivos y de la llegada a la madurez investigadora de, al menos, dos nuevas generaciones. En el extranjero, la apertura archivística también se ha producido pero, por definición, no ha sustituido a las riquísimas fuentes españolas.

En ambos casos hay que añadir otros factores comunes: el desarrollo de nuevos enfoques (historia social, cultural, de género, de mentalidades, de costumbres, etc.), la hibridación del estrictamente historiográfico con el de otras disciplinas (sociología, politología, sicología, antropología, arqueología, etc.) y el intercambio de experiencias entre historiadores espańoles y extranjeros. Escribir sobre la guerra civil se encuadra hoy en un entramado institucional y relacional que no había existido. El conocimiento científico ha aumentado exponencialmente.

Sin embargo, persisten mitos y falacias. Para un sector de la literatura neofranquista (como nos referiremos a ella en este artículo) no ha habido, en puridad, grandes innovaciones conceptuales o metodológicas. Explicar las causas de esta discrepancia entre los enfoques mitográficos y falaces y un conocimiento científico relativamente consolidado excede de los límites de este articulo. $\mathrm{Me}$ limito a recordar que también existen diferencias en relación con fenómenos de vasta importancia. El «negacionismo» de la Shoah no ha desaparecido. La atracción de resurgidos populismos y nacionalismos ha inducido peligrosas reorientaciones y exacerbado la percepción presentista del pasado. La guerra fría sigue gravitando en muchos historiadores. La racionalidad de la Ilustración y del trabajo científico coexiste con las más grotescas teorías y afirmaciones en el inabarcable mundo del ciberespacio.

\section{PARAdigmas De LA GUERRA CIVIL}

En la dictadura franquista cristalizó un paradigma cerrado que fue defendido con todos los resortes de la represión política y cultural, de la censura y del poder coercitivo del Estado. Ayudado por el sistema educativo desde 1939 en adelante y con la impagable aportación nacional-católica. Solo en los sistemas comunistas cabe hallar en Europa una ambición similar, aunque más prolongada y acentuada.

El paradigma franquista influyó decisivamente en la mentalidad y en la formación e información de amplios sectores de la sociedad española, generalmente del lado de los antiguos vencedores. Se mantiene en buena medida 
en la actualidad, convertido en un revoltijo de mitos y falacias inasequibles a los resultados de la investigación.

En el lado de los vencidos no cristalizó un paradigma uniforme. La catastrófica derrota, con su cortejo de desavenencias profundas, no permitió consolidar explicaciones compactas. La rivalidad política se tradujo en una amplia floración de ensayos y obras memoriales caracterizada en general por un claro deseo de exculpación o de inculpación. En la historiografía actual no es difícil encontrar ecos de tales querellas.

Las pugnas ideológicas de tipo endógeno (intra-españolas) se vieron alimentadas por el impacto de la guerra fría. Los anglonorteamericanos incidieron en ellas gracias a la actuación de mecanismos que ahondaron las divergencias del exilio. El IRD (Information Research Department) británico y la CIA (a través del Congreso por la Libertad de la Cultura) apoyaron todas las interpretaciones no comunistas de la guerra civil e influyeron en autores anarquistas, poumistas, excomunistas y socialistas. El antiguo poumista Julián Gorkin, a sueldo norteamericano, escribió como si se hubiera tratado de un intento de establecer una república popular a remedo de las que la URSS fue creando tras el conflicto mundial en los países de la Europa central y oriental. El periodista galés, otrora pro-comunista y ya acaudalado agente de la propiedad inmobiliaria en California, Burnett Bolloten, pasó treinta años trabajando en una obra en la cual la guerra civil aparece en gran medida como la cortina tras la cual se ocultaron los aviesos designios soviéticos. Todo esto vino como anillo al dedo a la dictadura.

Los puntos fundamentales del paradigma franquista (ligeramente retocado en una versión adaptada al momento presente) pueden resumirse como sigue:

En lo que se refiere al origen de la guerra civil:

1. Fue la consecuencia lógica, y prácticamente inevitable, del fracaso de una República sectaria y excluyente que no supo asentar un régimen que concitara el afecto de la inmensa mayoría del pueblo español. Los nuevos detentadores del poder ni lo intentaron.

2. La República, en particular durante el bienio republicano-socialista de 1931 a 1933 y la primavera del Frente Popular, fue sumamente disgregadora. Estuvo dirigida por un conjunto de fuerzas (socialistas, comunistas, masones, etc.) que constituyó, en puridad, la manifestación de la «anti-España» (posteriormente rebautizada como «fuerzas revolucionarias»).

3. Estas últimas desarrollaron una amplísima actividad de subversión del orden económico, político y social heredado y negaron el pan y la sal (con frecuencia la vida misma), a los elementos católicos, conservadores y, en último término, patrióticos.

4. Una parte de las fuerzas políticas y sociales situadas detrás del Gobierno que emergió de las urnas, por pequeña diferencia, en febrero de 1936 (antes presentado como peón moscovita y hoy simplemente como revolucionario) fue manipulada por los comunistas con el fin de penetrar en la Europa occidental por el flanco español. 
5. En consecuencia, el movimiento que recurrió a las armas en julio de 1936 fue una medida desesperada para salvar una España presa del desorden, de asesinatos en cadena y de ataques a la Iglesia y a la propiedad. Impidió que la nación se despeñara por un ominoso precipicio.

6. El régimen republicano había perdido cualquier legitimidad que ostentase (para los más extremistas nunca existió) pero la revolución social que se desencadenó en la zona bajo su control, con la persecución y asesinato de millares de eclesiásticos y elementos de derechas, dio al traste con las briznas que le hubiesen quedado ${ }^{1}$.

En lo que se refiere al desarrollo de la guerra:

1. La República recibió ayuda masiva de la Unión Soviética, en consonancia con los perversos propósitos del Kremlin. También, en no extrańa coyunda, la Francia del Frente Popular se opuso a los «nacionales».

2. El apoyo externo recibido por estos últimos fue, sin embargo, limitado. Siempre se justificó por el inmenso acopio que los «rojos» hacían en el extranjero.

3. La disciplina, una voluntad férrea y el restablecimiento del orden fueron objetivos que las armas «nacionales», bendecidas por la Iglesia, persiguieron tenazmente. Al final alcanzaron la victoria.

4. Esta victoria fue conseguida esencialmente gracias al tesón, a la fortaleza y a la sagacidad del general Francisco Franco que, literalmente, salvó a la PATRIA (con mayúsculas) de perecer a manos de sus enemigos.

La dogmática afirmación de que la sublevación tuvo un sentido preventivo dura hasta nuestros días. Véase, por ejemplo, lo que escribe un eminente catedrático de Historia muy influyente en la Universidad San Pablo-CEU:

En la primavera de 1936 eran ya muchos los militares convencidos de que lo único que libraría a España de su disgregación, y de caer en manos de una dictadura marxista similar a la que sufría Rusia desde hacía ya más de quince años, era una acción armada encabezada por el ejército ${ }^{2}$.

La cita refleja la congelación del tiempo "histórico», el que existía en 1936, en tiempo actual. La única "prueba» de los asertos son los alegatos sobre unas actas de las reuniones de la Komintern en la primavera de 1936 que llegaron (no se explica cómo) a conocimiento de los «nacionales». Solo existieron en la imaginación de los proponentes del golpe militar ${ }^{3}$.

1. En la actualidad se cuenta ya con el esperado estudio de Eduardo González Calleja et al, La Segunda República Española, Barcelona, Pasado\&Presente, 2015, que está llamada a convertirse en una obra de referencia.

2. Luis E. Togores, Yagüe. El general falangista de Franco, Madrid, La Esfera de los libros, 2010, p. 171. En la página previa ensarta una serie de disparates sobre los «propósitos» de la Komintern que merecen figurar en cualquier antología de la mentira.

3. Además de los estudiados por Herbert R. Southworth, en El lavado de cerebro de Francisco Franco, Barcelona, Crítica, 2000, cabría añadir los que cito en Ángel Viñas, La conspiración del General Franco, edición ampliada, Barcelona, Crítica, 2012. 


\section{En lo que se refiere a las consecuencias de la guerra civil:}

1. La victoria la obtuvieron las fuerzas que representaban las mejores tradiciones de España que evitaron que sucumbiera ante las lacras que la habían desviado de su camino histórico: el socialismo, el anarquismo, el comunismo, el liberalismo desenfrenado. Todos ellos «revolucionarios». Franco aspiró a crear esa «nueva España» bajo un régimen «autoritario» que, como señala Stanley G. Payne, reanudaría eficazmente el élan regeneracionista de principios del siglo XX.

2. Esta «regeneración» únicamente podía impulsarse desde un Ejecutivo fuerte. Las modificaciones que tuvieron lugar en él se hicieron en condiciones cuidadosamente controladas. Existió, sí, una tentación «fascistizante» pero fue flor de un día. Un país católico como Espańa no podía refugiarse en doctrinas «totalitarias». Franco, desde fecha temprana, impulsó un proceso lento pero constante de «institucionalización» y "constitucionalización» de su régimen «autoritario».

3. Fue imprescindible centralizar el poder. Su ejercicio se elevó a la categoría de principio absoluto como reacción a la experiencia republicana de «devolución» a las nacionalidades históricas de una cierta capacidad de actuación. Se derogaron los estatutos vasco y catalán. El castellano quedó configurado como única lengua oficial. Autonomía se equiparó a separatismo.

4. La Segunda Guerra Mundial obstaculizó la obra de recuperación. Cuando se reconocieron "la razón de España» y la rectitud del Caudillo, este abrió las puertas a un proceso de desarrollo económico como el país no había conocido jamás en su historia.

En definitiva, un régimen nacido de una guerra civil necesaria sentó las bases para el crecimiento y transformación económica y social subsiguientes. Sin el franquismo no habría habido democracia en España.

Todos los asertos precedentes son, sin embargo, rigurosamente míticos o falaces. La labor de los historiadores genuinos los ha triturado y ello con independencia de su adscripción política o ideológica.

\section{LA CONTRAOFENSIVA NEO-FRANQUISTA}

No extrañará que en los últimos diez años haya aparecido, a modo de contraofensiva, un cierto revival neo-franquista que ha adoptado dos formas principales: una de tipo general e inmediata. Otra, más sofisticada y restringida.

La primera es obra de periodistas, divulgadores, "tertulianos» y aficionados. Tiene una gran capacidad de penetración ya que suele desarrollarse en el mundo digital y en ciertas redes sociales, todas ellas exentas lógicamente de cualquier control de calidad. También se ha apoyado en cadenas de radio y de televisión muy connotadas y entre las cuales sobresalen algunas próximas a la involutiva jerarquía de la Iglesia Católica española. Se caracteriza esencialmente por la ausencia de toda nueva base documental y nulas innovaciones metodológicas. 
Sus cultivadores afirman acudir a fuentes. No es en general cierto pero sí es típico su tratamiento: la distorsión, la omisión, la tergiversación y, llegado el caso, la falsificación como rasgos constantes. Salvo en plan de ejemplos de mistificación y de recepción en una sociedad todavía dividida por el recuerdo social de la guerra, su aportación al conocimiento historiográfico es nulo.

La segunda forma de contraofensiva es más reciente. Sus proponentes tienen formación académica y trabajan en ciertas Universidades, no muchas, españolas y extranjeras. Para la gran mayoría el tema de atención preferente no es la guerra misma sino sus antecedentes, quizá porque el estudio de la primera se ha profesionalizado extremadamente y no es fácil labrarse una reputación académica en tal ámbito. No postulan siempre el desemboque automático y casi garantizado de la República en el conflicto, pero su tratamiento de los años republicanos no deja demasiados resquicios a otra alternativa. Las izquierdas aparecen como las inspiradoras de una evolución profundamente negativa, que se aborda por lo general omitiendo en amplia medida la interacción de los condicionantes económicos, sociales y culturales.

El concepto de democracia se sustrae al tiempo histórico y se plantea en abstracto, como si la existente en los años treinta hubiera debido ser lo que hoy se entiende por tal. La argumentación prima el discurso político e ideológico por encima de los comportamientos efectivos. La ahistórica comparación con la transición de 1976 subyace a muchos de sus planteamientos.

La desfiguración de la experiencia republicana lleva a absolver a las derechas de casi toda responsabilidad por el estallido de la guerra. En tal sentido, esta forma de contraofensiva coincide con el postulado fundamental del paradigma franquista. No obstante la mayor parte de los historiadores de tal tendencia rechaza airadamente el que pueda acercárseles a los autores claramente proclives al franquismo y reivindican para sí un enfoque científico, alejado de cualquier preconcepción ideológica.

Ricardo Robledo ha resumido en diez puntos los principios básicos de esta contraofensiva académica:

1. Neutralidad científica en comparación con una presunta historia de combate y condena de la ideología porque, ya se sabe, los historiadores no han de tenerla.

2. Minusvaloración de la historia estructural y de clase. Las determinaciones estructurales son una "coartada exculpatoria para difuminar la responsabilidad concreta de los protagonistas».

3. Desidealización de la República, que dio paso «al período más siniestro de la historia contemporánea de España».

4. Énfasis en las denominadas políticas de exclusión ya que, en particular los socialistas, consideraron la República patrimonio suyo y se mostraron profundamente intransigentes. Nótese el toque presentista.

5. Radicalismo revolucionario (nada retórico) de la izquierda, que no defendía una democracia pluralista y que fue extremadamente violenta hasta culminar en el caos del Frente Popular.

6. La CEDA no fue el caballo del Troya del fascismo. Ni la CEDA ni la 
JAP utilizaron la violencia en las elecciones de 1936 como sí hicieron socialistas y comunistas. Hubo excesos verbales, pero la CEDA no vulneró la legalidad, salvo a fines de junio y principios de julio de 1936 y solo por parte de algunos cedistas. No hubo ninguno que participara en la conspiración relanzada en marzo.

7. El «bienio negro» no fue tan negro: «fue un periodo de rectificación, no de reacción»; los gobiernos del centro no fueron meros títeres de la derecha; procuraron mantener a la izquierda dentro de los límites de la convivencia y dar cabida a la derecha posibilista (CEDA). En la opinión de un eminente historiador italiano, Gabriele Ranzato, «octubre del 34, si no fue el comienzo de la guerra civil, sí fue su más importante premisa y, de alguna forma, su ensayo general». Desde estas posturas no extrañará la consecuencia a la hora de distribuir responsabilidades. Se retoman algunas de las ideas que afloraron en la Transición («todos fuimos culpables») y se llega, cuando más, a la

8. «Equiviolencia». No hubo planificación de la violencia azul. Términos como holocausto o genocidio son grotescos. Los crímenes republicanos obedecieron a la lógica revolucionaria de socialistas y comunistas. En la represión franquista no hubo planificación del exterminio y solo una parte minoritaria de las causas judiciales de la posguerra culminaron en condenas a muerte.

En el plano metodológico, una característica es constante:

9. El menosprecio de la memoria histórica, descalificada como «involución intelectual», que desempeña un «nefasto papel» y que ha derivado en disputas ideológicas «históricamente absurdas». El carácter presentista aparece evidente en alguna proposición tal como que «debe renunciarse expresamente a una memoria histórica que conduzca nuevamente al enfrentamiento civil entre los españoles». Cerremos, pues, un capítulo trágico. Todo lo anterior culmina en

10. La idealización del "espíritu de la transición», que puede peligrar si se da cancha abierta a la memoria histórica. Si la guerra supuso el final de la República, la democracia habría sido fruto del franquismo. Un historiador francés que vio la luz, François Furet, caracterizó a Franco de «oligarca astuto». No fascista ${ }^{4}$.

En relación con la guerra misma buena parte de los autores la abordan fundamentalmente desde el punto de vista de la represión. La de los «revolucionarios» empezó a estudiarla el régimen triunfante desde antes de la victoria y desembocó en la llamada Causa General. La investigación no enfeudada a las falacias neo-franquistas ha destacado sus graves carencias metodológicas y su inflación de víctimas. Sin embargo en la contraofensiva académica la represión de los sublevados se minora y se hace hincapié en su

4. El lector que quiera profundizar en estos aspectos puede referirse al artículo de Robledo «Historia científica vs historia de combate en la antesala de la guerra civil», Studia Historica. Historia Contemporánea, vol. 32, pp. 75-94, 2014. 
carácter reglado bajo el paraguas de la justicia militar de la época. Destaca en este ámbito un historiador hispano-británico, Julius Ruiz.

Siguiendo una rancia tradición franquista, el segundo tema más prominente estriba en minusvalorar la aportación a Franco de las ayudas extranjeras, en particular la nazi. El objetivo es obvio: conviene reducir el apoyo foráneo a los vencedores y acentuar el que los soviéticos prestaron a los republicanos. Por supuesto que las concomitancias financieras de los primeros con los sectores más agresivos del capitalismo español y extranjero (particularmente británico y norteamericano) se orillan en todo lo posible.

Recientemente ha aparecido una variante, muy propagada por Michael Seidman: la disciplina en el manejo de los resortes económicos y la sistemática asignación de recursos a la guerra determinaron esencialmente la «victoria nacional». La guerra fue esencialmente civil. El contexto internacional no fue dirimente.

Muchos autores que militan en esta contraofensiva son protegidos del profesor Payne, catedrático emérito de la Universidad de Wisconsin ${ }^{5}$, darling de la derecha espańola y cuya evolución ideológica desde los lejanos ańos sesenta y setenta del pasado siglo merecería un análisis detallado. Payne ha recorrido todo el arco de los planteamientos neo-franquistas desde su análisis de los años republicanos hasta el comienzo de la transición. A lo largo de por lo menos cuatro décadas de continua producción de libros, con frecuencia siguiendo el seguro método del copy and paste, no ha puesto jamás sus pies en ningún archivo español, salvo alguna que otra esporádica visita al de la Fundación Nacional Francisco Franco.

\section{Soportes POLÍticos E INSTITUCIONALES}

El revival neo-franquista no es un entretenimiento intelectual. Se apoya en una sólida evolución política. En primer plano figura el embate mediático y periodístico tras la llegada al Gobierno, en 1996, del Partido Popular y la involución experimentada en la jerarquía de la Iglesia Católica española, empeńada en beatificar cuando menos a todos los mártires que sea posible. También lo han favorecido las controversias desatadas en torno a la denominada Ley de Memoria Histórica de 2007, aprobada por el Parlamento a propuesta del Gobierno del PSOE y en contra de la oposición del Partido Popular, pero con el apoyo de los demás partidos del arco parlamentario. Una ley demasiado corta y desprovista de toda operatividad.

Para un sector de la sociedad española y sus medios de comunicación ha resultado intolerable que el Gobierno central terciara, por primera vez, en el

5. No ha renunciado a prologar auténticos panfletos. Quizá los más sangrantes son los escritos por algunos pornógrafos de la historia. Su reciente biografía de Franco (en conjunción con el periodista Jesús Palacios) ha sido objeto de un tratamiento pormenorizado en el número 1 extraordinario de 2015 de la revista digital Hispania Nova: http://e-revistas.uc3m.es/index.php/ HISPNOV/issue/view/448 
debate que en la sociedad civil habían despertado las continuas exhumaciones de víctimas de la violencia franquista en las denominadas "fosas del olvido". Que los historiadores exigieran más recursos, más medios y más facilidades con el fin de continuar poniendo al descubierto estas dimensiones amargas del pasado oculto resultaba intolerable.

En consecuencia desde 2012 se ha producido un continuo vaciamiento de la ley, aunque no su abrogación, algo que hubiese sido perfectamente factible dada la mayoría absoluta parlamentaria del PP. El Gobierno optó por la supresión de casi todas las ayudas para apoyar las exhumaciones. Es también notable la renuencia gubernamental a prestar la menor atención a las numerosas y repetidas recomendaciones de Naciones Unidas. O su rechazo explícito de cualquier condena del franquismo.

Dos fenómenos poco aireados son extraordinariamente sintomáticos. El progreso en el desentrańamiento del pasado es función de dos variables: la identificación de nueva evidencia primaria relevante de época y la aplicación de los enfoques metodológicos pertinentes. El gobierno del PP no puede obstaculizar estos últimos pero sí los primeros. Rápidamente se adoptaron medidas para paralizar el continuo progreso realizado hasta 2011 en materia de accesibilidad a los archivos. Algo que ni siquiera había ocurrido durante las dos legislaturas conservadoras anteriores (1996-2004). La ministra de Defensa socialista Carme Chacón dejó a finales de 2011 un total estimado de 10.000 documentos para desclasificar por el Consejo de Ministros. Previamente se habían realizado las necesarias comprobaciones para evitar la revelación de datos que pudiesen afectar a los secretos de la Defensa Nacional (hay que suponer que no habría muchos) y al honor de las personas. El nuevo ministro Pedro Morenés se opuso radicalmente a elevar la propuesta al Consejo.

Hasta 2011 la consulta de los riquísimos archivos del Ministerio de Asuntos Exteriores se hacía con un plazo de acceso de en torno a 25 años. El ministro José Manuel García-Margallo se aprovechó, torticeramente, de un acuerdo secreto del Consejo de Ministros socialista de octubre de 2010 para cerrar de golpe su acceso. Trasladados al Archivo General de la Administración traspasó responsabilidades a la Secretaría de Estado de Cultura. No se aprovechó la Ley de Transparencia para establecer un criterio operativo de consulta. La documentación que hasta aquel momento había podido verse llegaba más o menos hasta 1985. En la práctica hoy es difícil pasar de 1968, año de la ley franquista de secretos oficiales.

En este clima la explotación político-demagógica de la visión neo-franquista aplicada al presente se ha convertido en algo de rigor. Acudamos, a título de mero ejemplo, a la destacada política del PP Esperanza Aguirre:

No hay que ser un historiador avezado (sic), basta con ser un lector mínimamente crítico de los libros de Historia (sic), para saber que la II República fue un auténtico desastre para España y los españoles $(s i c)$. Es cierto que fue recibida con la esperanza de que cerrara la crisis que había abierto el golpe de Estado de Primo de Rivera (absolutamente incruento y que pronto contó con la complicidad del Partido Socialista, la UGT y Largo Caballero, todo hay que decirlo). Pero también es cierto que muchos 
políticos republicanos utilizaron el régimen recién nacido para intentar imponer sus proyectos y sus ideas -en muchos casos, absolutamente totalitarias (sic) - a los demás, y que faltó generosidad y patriotismo $(s i c)$. El resultado fue una guerra salvaje que algunos quieren que siga influyendo en la vida política de hoy ${ }^{6}$.

El revival se reflejó incluso en ciertas entradas del Diccionario Biográfico Español (DBE) promovido por la Real Academia de la Historia (RAH). Un trabajo considerable, y que se remonta a los más remotos tiempos en la evolución histórica de lo que llegaría a ser España, se vio profundamente deslucido por la proliferación de nociones franquistas y, en ocasión, incluso de la extrema derecha actual. Las entradas afectadas corresponden a protagonistas de los períodos más debatidos de la historia contemporánea española: República, guerra civil, franquismo. La controversia saltó a los medios y redes sociales. Muchas de tales entradas, incluida la del propio Franco, no solo contienen una terminología impropia sino errores de bulto e incluso groseros ${ }^{7}$.

En la literatura se han manejado diversas hipótesis complementarias para explicar el crecimiento de tales corrientes. Algunos hacen hincapié en la atracción ideológica. Otros en los encantos crematísticos. No falta quienes las entienden como resultado de un esfuerzo de marketing basado en los modernos mecanismos de divulgación y persuasión sociales. Tampoco los que aducen motivos coadyuvantes varios: el franquismo sociológico todavía presente en la sociedad; el que la derecha haya querido apuntarse victorias en el terreno de la política práctica aprovechando su temporal mayoría absoluta en el Parlamento y en contra de las preferencias modernizadoras, laicistas y de ampliación de las libertades civiles de buena parte de la sociedad; el que busque alivio en la ofensiva contra las corrientes que realzan los desmanes cometidos por sus antepasados políticos, sociológicos y, en ocasiones, físicos. Todo lo anterior es plausible. Hay más.

\section{JUSTIFICACIÓN Y PROYECCIÓN}

Franco y su dictadura siempre tuvieron necesidad de dotarse de una base justificativa. La victoria en una guerra bendecida por la Iglesia Católica fue necesaria, a decir verdad imprescindible, pero nunca suficiente. Las bases conceptuales e ideológicas quedaron establecidas en el Dictamen sobre la ilegitimidad de poderes actuantes en 18 de julio de 1936, realizado por un selecto

6. $A B C, 28$ de enero de 2013.

7. Empezando por las referidas a Franco y a Azańa. Los autores son dos connotados historiadores: Luis Suárez y Carlos Seco. La de Mola tampoco se queda corta y, quizá por casualidad, fue encargada a un general hiper-franquista. En el momento de redactar estas líneas la nueva directora de la RAH, la profesora Carmen Iglesias, ha anunciado la revisión de una serie de entradas on line. En reacción a las abusivas interpretaciones del DBE surgió Viñas, Ángel (ed.), En el combate por la historia, Barcelona, Pasado\&Presente, 2012, y para el tema objeto de este artículo en especial la contribución de Reig Tapia, Alberto y Viñas, Ángel, «Residuos y derivaciones franquistas». 
grupo de militares, académicos, intelectuales y políticos por orden de Franco y supervisado por su cuñado y, a la sazón, ministro de la Gobernación Ramón Serrano Suñer. Gran parte del revival neo-franquista, sobre todo el dirigido al gran público, encuentra en él sus fuentes nutricias ${ }^{8}$. La justificación fue densificándose a lo largo del tiempo con nuevas aportaciones y matices. No entraré en esta materia, suficientemente conocida. Me interesa más destacar un vector que me ha costado trabajo identificar.

Este vector tiene que ver con la puesta en práctica sistemática del mecanismo de proyección. Es decir, la imputación a otro, con carácter negativo y con fines de auto-defensa, de rasgos de comportamiento que son propios. Quien tiene éxito en alcanzar un nivel elevado de proyección se siente más seguro y está en mejores condiciones de proyectar su éxito hacia sus adversarios. El resultado, a sus propios ojos, revalida su actuación. Cuando ello se mezcla con la necesidad de justificación la combinación resultante proporciona un profundo sentimiento de fortaleza y de seguridad.

Lo que une a seudorrevisionistas, ya sean de pacotilla o de corte académico, es una misma forma de encarar la realidad histórica: la conveniencia de imputar al adversario ideológico o político (socialistas, comunistas, anarquistas, liberales, ateos, masones, librepensadores, etc., es decir, a lo que solía denominarse la "anti-Espańa») un tipo de comportamiento que equivale, simplemente, a las escamoteadas actuaciones de los vencedores.

En la medida en que la postura individual y un cierto nivel de cohesión colectiva se mantengan por razones culturales (hay un público que está dispuesto a defender con uñas y dientes esas mismas ideas sobre el pasado y que siempre necesita una alimentación renovada), económicas (compra lo que le echen) y políticas (de rechazo del otro), la proyección seguirá funcionando. Surge así la cuestión de identificar esas actuaciones escamoteadas. Para ello es necesario destacar comportamientos que llevaron a la guerra civil estableciendo la crucial diferencia, que conoce todo estudiante de lógica, entre condiciones necesarias y condiciones suficientes.

Las primeras son aquellas que deben darse para que pueda tener lugar un fenómeno determinado. En el caso de los de carácter social tales condiciones son complejas y muy diversas. Así, por ejemplo, tenemos en primer lugar la sed de reformas económicas, sociales, políticas y culturales que España venía arrastrando desde los comienzos de la Restauración y que se agudizó durante la dictadura primorriverista. Esta fue una condición necesaria para que desde las posiciones de poder económico, político y social tradicionales emanara una fuerte oposición a cualquier cambio en profundidad de la situación que había cristalizado a finales de 1930.

Tal oposición, desarticulada tras el imprevisto advenimiento de la República, atravesó fases muy conocidas y alimentó la sublevación de 1932. Aunque borrosa, los «héroes del 10 de agosto», por utilizar la terminología franquista,

8. El análisis más reciente de las falacias neo-franquistas se encuentra en Sánchez Pérez, Francisco (coord.), Los mitos del 18 de Julio, Barcelona, Crítica, 2013. 
se levantaron contra las reformas introducidas por la conjunción republicanosocialista. La misma oposición, mucho más estructurada y organizada, volvió a la carga tras las elecciones de febrero de 1936.

La importancia de este tipo de condiciones, que también suelen denominarse estructurales, fue muy enfatizada desde los primeros estudiosos que, sin seguir el canon que ya empezó a acuñarse en los albores de la dictadura franquista, trataron de explicar lo que no dejaban de ver como una anomalía. ¿Por qué hubo una guerra civil en España? Pionero entre ellos fue Gerald Brenan. Detrás de él toda una serie de autores (Pierre Vilar, Manuel Tuñón de Lara, etc.) reforzó la significación de tales condiciones. Con razón.

Los primeros balbuceos oficiales de la explicación de la génesis de la guerra, los que hicieron los jefes y oficiales del Servicio Histórico Militar en los años cuarenta con todas las bendiciones de la jerarquía castrense, también se remontaron hasta el siglo XIX (e incluso ocasionalmente hasta el XVIII). Su intención estribó en explicar la irrupción de la malhadada República como el último jalón de una evolución secular de decadencia promovida por la «antiEspaña».

Tales factores no tenían por qué conducir necesariamente al estallido de 1936. Hoy se admite por lo general que si no se hubieran producido ciertos hechos en el período que llega hasta las elecciones de febrero de 1936, la evolución ulterior hubiese podido ser diferente. Sin ánimo exhaustivo alguno cabe mencionar la arbitraria destitución de Manuel Azaña como presidente del Gobierno en 1933 por el presidente de la República Alcalá-Zamora. Esto abrió la puerta a nuevas elecciones que no ganaron los republicanos burgueses y los socialistas que concurrieron desunidos. $\mathrm{O}$, segundo ejemplo, el no nombramiento de Gil Robles por Alcalá-Zamora como presidente del Gobierno en diciembre de 1935 a raíz de la dimisión de Lerroux tras el escándalo del estraperlo y la humillante imagen de los miembros del Partido Radical involucrados en el affaire. $\mathrm{O}$, tercer ejemplo, la posibilidad de que el nuevo presidente del Gobierno Manuel Portela Valladares hubiese aceptado la declaración del estado de guerra que le pidieron los militares (entre ellos Franco) y anulado el resultado de las elecciones subsiguientes. Es difícil pensar que la izquierda hubiese tenido la capacidad de montar una oposición efectiva. The road taken, por utilizar la terminología anglosajona, indujo la evolución que realmente tuvo lugar. La que no se tomó (the road not taken) ha de quedarse en mero ejercicio especulativo.

Sentado lo que antecede, lo que determinó la sublevación de julio de 1936 fueron ciertas condiciones suficientes, es decir, aquel tipo de condiciones que cuando se producen conducen a un cierto resultado y no a otro. En la primavera de 1936 sobresalen dos:

- La ineficacia del gobierno en cortar la conspiración, algo sobradamente conocido, pero no siempre bien explicado,

- La consecución por parte de los conspiradores de abundante material bélico moderno, inexistente en Espańa, y apto para una guerra corta.

Esto se ha descubierto recientemente, pero en la literatura neo-franquista aparecida después no se ha tomado nota. Que el $1^{\circ}$ de julio de 1936 Pedro 
Sainz Rodríguez firmara con una empresa italiana el suministro urgente (en el mismo mes) de aviones de caza y bombardeo y que muchos otros se comprometieran para sucesivas remesas en agosto no parece que a los autores de aquella orientación les plantee problema alguno. Sin embargo, el tema no es baladí.

En primer lugar porque fue algo que la cúpula militar preparadora de la sublevación tuvo que saber. Quien llevó la vara alta en las negociaciones con los italianos y con el financiador de las mismas, el banquero Juan March, fue la cúpula política de Renovación Española. Y ¿quién formaba tal cúpula?: José Calvo Sotelo (el "proto-mártir» del franquismo), Antonio Goicoechea y Pedro Sainz Rodríguez. Todos ellos conservadores, monárquicos alfonsinos, ligados a la revista Acción Española y, en el primero de los casos, con un ya marcado sesgo filofascista. Entre los militares que verosímilmente estuvieron mezclados figuran en lugar prominente los generales Alfredo Kindelán y Luis Orgaz, este último prontamente arrinconado por el Gobierno a Gran Canaria donde no es imposible que pusiera en antecedentes a Franco. Kindelán debió de desempeñar un papel esencial no solo porque era un frecuente visitante en Roma sino porque era el único con conocimientos técnicos suficientes para asesorar a los negociadores sobre el tipo de aviones que convenía adquirir?

Con lo que antecede tenemos el primer ejemplo de proyección: la imputación a los comunistas de preparar una revolución con el apoyo moscovita cuando fueron los mismos monárquicos quienes preparaban la sublevación con abundante $y$ moderna ayuda fascista.

Otro ejemplo: la imputación a las autoridades republicanas de la exclusiva responsabilidad por el desorden en la primavera de 1936 cuando fueron los conspiradores civiles y militares quienes necesitaban crear la percepción de un estado de anarquía e inestabilidad total. Este tema desaparece en todas las versiones de las falacias neo-franquistas. La discusión la han llevado, por el contrario, a un terreno en el que Calvo Sotelo y Gil Robles fueron durísimos en sus denuncias en el Parlamento acerca de la situación inaceptable que se había instaurado en España.

Poca atención han prestado, valga el caso, los autores de una vergonzosa y reciente biografía de Franco a las puntualizaciones críticas desarrolladas en los últimos años por Rafael Cruz y Eduardo González Calleja, este último en numerosas obras. Por olvidar, hasta olvidan el interesante documento, que ya exhumó Ismael Saz hace casi cuarenta años, que mostraba cómo precisamente Goiecoechea acudió a Ciano en junio de 1936 a pedir fondos fascistas para financiar a los «grupos de acción» (léase los pistoleros falangistas y otros) porque los dineros monárquicos se habían agotado.

9. Ángel Viñas, «La connivencia fascista con la sublevación y otros éxitos de la trama civil», en la obra coordinada por Sánchez Pérez. 


\section{Otros ejemplos de proyección}

Son tres los grandes casos que los autores neo-franquistas suelen esgrimir en contra de la República en guerra: a) se trató, en realidad, de una «tercera República»; b) fue una marioneta soviética; c) alargó innecesariamente el conflicto.

La tercera República es una de las caracterizaciones favoritas de Payne ${ }^{10}$. Su curiosa tesis se basa en que, estallada la guerra, el Gobierno republicano cayó en manos de extremistas que se lanzaron con ahínco a la total subversión del orden político y social con la que tanto habían sońado. En consecuencia el aparato gubernamental fue puesto al servicio de un proyecto revolucionario. En realidad, aunque dicho aparato se desplomó temporalmente, los gobiernos de Largo Caballero se preocuparon de poner de nuevo en pie las instituciones y de restaurar la autoridad del Estado. Los gobiernos Negrín continuaron tal política de forma más eficiente. La legalidad se mantuvo adaptada a las nuevas circunstancias. No de otra forma procedieron democracias como las que sufrieron el embate del Eje en la Segunda Guerra Mundial. Ejemplos: el más señero, el Reino Unido; el más complicado, Dinamarca bajo la ocupación. En el extremo opuesto: la Francia de Vichy y el gobierno noruego colaboracionista de Quisling. Sin embargo los autores neo-franquistas no ven nada extraordinario en el establecimiento de un régimen totalmente nuevo en la zona sublevada, apoyado en las bayonetas y que no tardó en desembocar en una dictadura en la que prevaleció desde el comienzo hasta el final el concepto nazi del Führerprinzip que omiten siempre cuidadosamente.

Una marioneta soviética con Negrín a la cabeza traslada las curiosas concepciones del autor galés y excorresponsal en España Burnett Bolloten. Para este denodado autor la recuperación de la autoridad del Estado fue simplemente una argucia comunista. Hizo escuela sobre todo en la historiografía anglosajona (Payne es uno de sus discípulos) ${ }^{11}$. Durante la guerra fría encajó como un guante en la perspectiva entonces dominante del post hoc ergo propter hoc ${ }^{12} . \mathrm{Si}$ hubo una intervención soviética de aviesos propósitos es «lógico» que Moscú tratara de poner bajo su control al Gobierno republicano. En realidad, fueron los fascistas italianos quienes más interesados estuvieron en exportar a España su propio modelo. Sus intentos pronto terminaron con un fracaso. Los nazis no trataron de exportar el suyo, pero su influencia fue muy superior y determinó numerosas modalidades de la política de represión, la alineación franquista en política exterior y la importación de principios básicos que fortalecieron el entramado institucional y jurídico de la incipiente dictadura franquista. Negrín y los socialistas rechazaron en tres ocasiones deseos de Stalin muy queridos.

10. No le corresponde el invento. Ya lo había desarrollado el coronel José Manuel Manuel Martínez Bande, del Servicio Histórico Militar.

11. Su obra acaba de publicarse en francés pero ya los historiadores conservadores de esta nacionalidad se habían servido de ella.

12. Falacia lógica que encadena dos hechos X y Z. Si Z se produjo después de X, X debió de ser la causa de Z. Confunde secuencia temporal y casualidad. 
Franco cedió ante Hitler tras la batalla del Ebro para conseguir la continuación de los suministros alemanes ${ }^{13}$.

La República alargó el conflicto que no podía ganar. Quien lo hizo fue, sin embargo, Franco. Esta afirmación es anatema para los historiadores neofranquistas y para algunos que, sin serlo, han empeñado una buena porción de su prestigio en negarla. Los historiadores militares han determinado varios momentos en los que, de haber tomado Franco otras decisiones estratégicas, la resistencia republicana se hubiera colapsado ${ }^{14}$. Si bien estos argumentos contienen un cierto elemento de especulación, hay un hecho que no la admite. Se trata de la renuencia de Franco, tras tomar Lérida el 6 de abril de 1938, a continuar el despejado avance hacia Barcelona, donde el Gobierno republicano estaba sumido en su más profunda crisis de toda la contienda, las posibilidades de resistencia eran escasas y el Ejército Popular no había podido adoptar todavía medidas frente al riesgo de colapso inmediato. Franco se inclinó por reorientar la ofensiva hacia Valencia en contra de la opinión de sus generales. Las explicaciones que dio en la postguerra (quería conquistar la rica huerta valenciana) son absurdas. Los autores neo-franquistas hacen hincapié en que no quiso provocar una intervención de Francia o que se inclinó ante Hitler. Se ignora la postura en contra del Comité Permanente de la Defensa Nacional francés del 16 de marzo precedente que el mariscal Pétain, vicepresidente del mismo, comunicó a Franco inmediatamente. El vicepresidente del Gobierno franquista y ministro de Asuntos Exteriores, conde de Jordana, resumió ante el Consejo de Ministros la situación internacional, de la que no se desprendía ningún peligro, a finales de mes. La documentación se encuentra en los archivos del Ministerio de Asuntos Exteriores y la he reproducido en el CD que acompaña a mi trabajo citado en la nota 13.

\section{Conclusiones}

La relación de mitos y falacias neo-franquistas podría alargarse. De la guerra civil, que sigue levantando pasiones, casi todo lo que pueda descubrirse en el futuro es verosímil que ya se haya dicho en algún momento. La tarea del historiador, en un terreno tan trabajado, estriba esencialmente en pasar por el ácido test de la comprobación con las fuentes primarias relevantes de época lo que supera la prueba y descartar lo que no lo consigue. Hay cuestiones metahistóricas que, naturalmente, no son susceptibles de fácil contrastación, pero la aplicación sistemática del método empírico-inductivo es susceptible

13. Ángel Viñas, El honor de la República. Entre el acoso fascista, la hostilidad británica y la politica de Stalin, Barcelona, Crítica, 2008. Una reciente obra ha llevado a extremos absolutamente exagerados la dependencia estructural de Franco respecto al Tercer Reich. Pierpaolo Barbieri, Hitler's Shadow Empire. Nazi Economics and the Spanish Civil War, Harvard, Harvard University Press, 2015.

14. Resumidas en Gabriel Cardona y Juan Carlos Losada, Aunque me tires el puente. Memoria oral de la batalla del Ebro, Madrid, Aguilar, 2004, pp. 33 y siguientes. 
de generar conocimientos no triviales. Medidos por este rasero son numerosos los autores neo-franquistas cuyos trabajos no sirven para progresar en el conocimiento científico. No se trata de una cuestión de ideología, que nunca falta, sino de penosa reconstrucción de parcelas poco iluminadas, o aún ocultas, de un pasado que es incognoscible en su totalidad. 